\title{
Composition of Volatile Compounds of Horseradish Roots (Armoracia rusticana L.) Depending on the Genotype
}

\author{
Lolita Tomsone*, Zanda Kruma, Ruta Galoburda \\ Department of Food Technology, LLU \\ Thierry Talou \\ National Polytechnic Institute of Toulouse, France
}

\begin{abstract}
Horseradish is a perennial plant with significant antioxidant properties, and it contains about $0.2 \%$ to $1.0 \%$ of essential oil, mainly sinigrin, sinigrin-derived allylisothiocyanate and diallylsulphide. The aim of the study was to determine composition of volatile compounds of horseradish (A. rusticana L.) roots depending on the genotype. Volatiles from fresh horseradish roots of nine genotypes were extracted using solid phase microextraction with DVB/Car/PDMS fibre and were further analysed using gas chromatography-mass spectrometry. The volatile compounds were identified by comparing their mass spectra with mass spectral libraries (Nist98) and by calculating linear retention indexes and comparing them with the literature data. The studied horseradish genotypes differed both in the quantitative and qualitative content of aroma compounds. Totally 15 volatile compounds were detected, and their highest amount was found in genotype G12B. The main aroma compound of all horseradish samples was allylisothiocyanate, which formed $64-82 \%$ of the total identified volatile compounds. The obtained results were compared with those found in the literature. All horseradish samples contained significant amounts of phenylethylisothiocyanate (4-18\%) that is formed from glucosinolate - gluconasturtin. The study revealed that genotype has great influence on the content of volatiles in horseradish roots.
\end{abstract}

Key words: Genotype, horseradish, volatile compounds, allylisothiocyanate.

\author{
Abbreviations \\ $\mathrm{AC}$ - allylcyanate \\ AITC - allylisothiocyanate \\ ATC - allylthiocyanate \\ BITC - benzylisothiocyanate \\ BuITC - butylisothiocyanate \\ CETP - 1-cyano-2,3-epithiopropane \\ CPITC - cyclopentylisothiocyanate \\ DAS - diallylsulfide \\ EN - epithionitrile \\ IBuITC - isobutylisothiocyanate
}

\section{Introduction}

Horseradish (Armoracia rusticana L.) is a member of the family Brassicaceae. It is a perennial plant possessing a particularly pungent flavour and significant antioxidant properties. Horseradish is indigenous to Eastern and Northern Europe and the Mediterranean and is also cultivated in Central Europe. Horseradish root has a brown outer skin and a fleshy white interior. The root by itself does not give much aroma, but releases a pungent, burning, mustard-like aroma upon grating, cutting or shredding, and it disappears very quickly.

\footnotetext{
* Corresponding author's email:

Lolita.Tomsone@1lu.lv
}

$$
\begin{aligned}
& \text { IPITC - isopropylisothiocyanate } \\
& \text { ITC - isothiocyanate } \\
& \text { MITC - methylisothiocyanate } \\
& \text { ODN - oxazolidinethione } \\
& \text { PEITC - phenylethylisothiocyanate } \\
& \text { PETC - phenethylthiocyanate } \\
& \text { PITC - phenylisothiocyanate } \\
& \text { PPTC - phenylpropylthiocyanate } \\
& \text { TC - thiocyanate }
\end{aligned}
$$

Horseradish has a sharp, acrid, burning, bitter taste and it contains about $0.2 \%$ to $1.0 \%$ of essential oil, mainly sinigrin, sinigrin-derived AITC, DAS, PPTC and PETC (Raghavan Uhl, 2000).

ITCs are hydrolysed products of sulphurcontaining compounds called glucosinolates which occur naturally in cruciferous vegetables such as watercress, Brussels sprouts, broccoli, cabbage, kai choi, kale, horseradish, radish and turnip (Wu, Kassie, \& Mersch-Sundermann, 2005). Enzymes and substrates come in contact upon damage to plant tissues, such as during injury or 
chewing, resulting in hydrolysis of the glucosinolates to liberate glucose and sulfate and form unstable aglucones that spontaneously rearrange to form ITCs, TCs, nitriles, ENs, or ODNs (Rask et al., 2000; Matusheski \& Jeffery, 2001; Wittstock \& Halkier, 2002; Bones \& Rossiter, 2006). Hydrolysis reaction is catalysed by myrosinase bond to the cell wall (Neoh, Yamamoto, Ikefuji, Furuta, \& Yoshii, 2012).

The nature of the hydrolysis products depends on the structure of the glucosinolate side chain, the plant species, and the reaction conditions (Rask et al., 2000; Matusheski \& Jeffery, 2001; Wittstock \& Halkier, 2002; Bones \& Rossiter, 2006). The pH also affects the production of glucosinolate compounds. AC production proceeds at $\mathrm{pH} 4.0$ (low $\mathrm{pH}$ environment favours the formation of nitriles), whereas AITC is produced at pH 7.0 (Gil \& MacLeod, 1980; Bones \& Rossiter, 1996). At neutral $\mathrm{pH}$ and upon inactivation of a protein factor, for example, the epithiospecifier protein, the products are principally ITCs (Gil \& MacLeod, 1980; Bones \& Rossiter, 1996; Wittstock \& Halkier, 2002).

The complexity of the host plant glucosinolate profile is further influenced by the array of fission products that arise after tissue is damaged. Glucosinolates accumulate in cell vacuoles isolated from myrosinase, a thioglucoside glucohydrolase responsible for initiating glucosinolate degradation (Andreasson, Jorgensen, Hoglund, Rask, \& Meijer, 2001). Glucosinolates are $\beta$-thioglucoside $N$-hydroxysulfates with more than 120 unique side chains derived from common amino acids: Phe or Tyr which give rise to aromatic glucosinolates; Ala, Leu, Ile, Met, or Val that form aliphatic glucosinolates; and Trp that takes part in a reaction forming indole glucosinolates (Fahey, Zalcmann, \& Talalay, 2001; Halkier \& Gershenzon, 2006). The damage by insects or any kind of injury alter glucosinolate metabolism in cruciferous vegetables, and plants release a plethora of volatile compounds including indoles, monoterpenes and sesquiterpenes (Olsson \& Jonasson, 1994). While glucosinolates are major players in determining the chemo-ecological relationships between Brassicaceae hosts and their insect pests, other allelochemicals are likely to be involved (Bodnaryk, Luo, \& Kudryk, 1997; Pfalz, Vogel, Mitchell-Olds, \& Kroymann, 2007).

Glucosinolate (sinigrin) is hydrolyzed by thioglucosidase (myrosinase) producing CETP, AC, AITC, and ATC (Shahidi \& Gabon, 1990). Myrosinase has been suggested to be a cell wall or membrane-bound enzyme. Several researchers have reported that sinigrin is localized to protein bodies in aleurone-like cells, and is absent from myrosin cells. Glucosinolates are composed of a sulfonated oxime, a thioglucose group, and a variable carbon R-group, which determines the name of the glucosinolate compound (Whitmore \& Naidu, 2000). Myrosinase enzyme acts on sinigrin to give AITC as the major product, which gives horseradish its burning taste (Raghavan Uhl, 2000; Whitmore \& Naidu, 2000).

Investigations about glucosinolates and AITC have been carried out for several decades, and almost 40 years ago it was determined that more than $80 \%$ of all glucosinolates identified are in the family of Brassicaceae, considered as a chemotaxonomic criterion for Brassica classification (Kjaer, 1976). Several authors have reported on the content of glucosinolates and AITC in plants, for example, cabbage varieties contain from 4 to $146 \mathrm{ppm}$ of AITC, from 0 to $2.8 \mathrm{ppm}$ of BITC, and from 1 to $6 \mathrm{ppm}$ of PEITC. In papaya during growing, BITC concentration in seeds has increased, whereas in pulp - decreased (Whitmore \& Naidu, 2000). Mustard seeds have been observed to contain about $93 \%$ of sinigrin (Shahidi \& Gabon, 1990). In broccoli, the ITC sulforaphane has not been found in an intact plant, but has been actually derived from its precursor - glucoraphanin (Dinkova-Kostova, 2008). The research data shows that in the mid-vein and periphery of A.thaliana leaves, glucosinolates have been detected at higher levels than in the inner leaf lamina (Shroff, Vergara, Muck, Svatos, \& Gershenzon, 2008).

In Capperis grandis L. roots, also 4,5,6,7-tetrahydroxydecyl-ITC has been identified (Gaind, Gandhi, Junega, Kjær, \& Juhl, 1975). As the main glucosinolate in seed oil and aerial parts of caper, glucocapperin has been identified (Matthaus \& Özcan, 2002), whereas in oil from caper leaves 2-hehenalbutyl-ITC and IPITC (Afsharypuor, Jeiran, \& Jazy, 1998). Research on commercial caper has shown that the major glucosinolate in this plant is MITC, followed by BITC (Romeo, Ziino, Giuffrida, Condurso, \& Verzera, 2007; Tlili et al., 2011).

PEITC exists in nature as gluconasturtin, and in particularly high levels is found in watercress (Fenwick, Heaney, \& Mullin, 1983). Among ITCs, PEITC has been extensively investigated for its chemopreventive action. PEITC is able to inhibit chemically induced lung, forestomach and esophageal tumorigenesis effectively (Wu, Kassie, \& Mersch-Sundermann, 2005). Some 
researchers have determined that different cultivars of the same species show different levels of AITC (Mayton, 1996).

ITC has a high biological activity. Korean researchers have reported that AITC is the most effective antimicrobial compound compared to garlic oil and trans-cinnamaldehyde (Gamage, Park, \& Kim, 2009). Addition of AITC (less than 0.1\%) to kimchi, a traditional fermented Korean dish, is an effective way of enhancing its shelf-life (Ko, Kim, \& Park, 2012). In China, ITCs (AITC, n-PITC and IBuITC) isolated from Brassicaceae family plants have been used to avoid Chongcai paste flavour and colour changes during the storage ( $\mathrm{Li}, \mathrm{Xue}, \mathrm{Xu}$, Ren, \& Pan, 2012). Italian researchers have reported on the use of glucosinolate-derived ITC for preserving fruits, and the results showed that the analysed ITC (BITC, butenyl-ITC, AITC and others) had beneficial effect on stone fruit quality during storage (Mari, Leoni, Bernardi, Neri, \& Palmieri, 2008).

Many ITCs have proved to be effective chemopreventive agents against carcinogen-induced cancers in experimental animals (Wu, Kassie, \& Mersch-Sundermann, 2005). Also horseradish has beneficial effect on human health - traditionally it was used by Europeans to treat gout, kidney stones, asthma, and bladder infections. Horseradish was also used in Europe to prevent scurvy before vitamin $\mathrm{C}$ was discovered. Grated horseradish mixed into a paste is a home remedy for chest congestion and stiff muscles because it brings blood to the surface of the skin and warms the skin. Horseradish has antioxidant and antimicrobial properties (Raghavan Uhl, 2000).

Several genotypes of horseradish are included in the collection of vegetable genetic resources of Latvian origin in the Pūre Horticultural Research Centre. Until now, biologically active substances of horseradish have not been studied in Latvian horseradish collection. No references concerning the chemical composition of the volatiles of this plant were found in the literature.

The aim of the present study was to determine the composition of volatile compounds of $A$. rusticana $\mathrm{L}$. roots depending on the genotype.

\section{Materials and Methods Plant material}

Nine genotypes of horseradish (Armoracia rusticana L.) were collected at the Pūre Horticultural Research Centre collection field (latitude $-57^{\circ} 03^{\prime} \mathrm{N}$; longitude $-22^{\circ} 91^{\prime} \mathrm{E}$ ). All genotypes were of Latvian origin (from different regions) with the exception of genotype No. 2 originating in Belarus. The genotypes were marked as follows: G1 - genotype 1; G2 genotype 2; G3 - genotype 3; G12B - genotype 12B; G104 - genotype 104; G105 - genotype 105; G280 - genotype 280; and G281 - genotype 281. The horseradish roots were harvested in September 2011 to determine composition of volatile compounds. Analyses were performed within two weeks after harvest. Freshly harvested roots were washed, peeled, homogenized and immediately analysed.

\section{Solid phase microextraction (SPME)}

Volatiles from the horseradish roots were extracted using SPME. A total of $5 \mathrm{~g}$ of a sample was weighed into a $20-\mathrm{ml}$ headspace vial and capped with a septum. For SPME extraction, a divinylbenzene/ carboxen/polydimethylsiloxane (DVB/Car/PDMS) fibre (Supelco Inc., Bellefonte, PA, USA) was used. The headspace SPME is based on the absorption of the analytes on a fibre coating placed in the sample's headspace volume and on the partition of the target analytes between the sampling matrix and the fibre. SPME parameters were: incubation time - $10 \mathrm{~min}$; extraction temperature $-35 \pm 1{ }^{\circ} \mathrm{C}$; and extraction duration $-10 \mathrm{~min}$.

After the extraction, the volatile compounds were thermally desorbed and transferred onto the chromatographic column where they were separated. Desorption parameters: $15 \mathrm{~min}$ at $250{ }^{\circ} \mathrm{C}$. That time was enough to ensure total desorption. Finally, the volatile compounds were transferred to the mass spectrometer for their identification.

\section{Gas chromatography-mass spectrometry analysis (GC/MS)}

For analysis of the SPME extracts, a Perkin Elmer Clarus $500 \mathrm{GC} / \mathrm{MS}$ and an Elite-Wax ETR columns $(60 \mathrm{~m} \times 0.25 \mathrm{~mm}$ i.d.; $\mathrm{DF}-0.25 \mu \mathrm{m})$ were used. Working conditions: injector $-250{ }^{\circ} \mathrm{C}$; transfer line to MSD $-260{ }^{\circ} \mathrm{C}$; oven temperature start $-40{ }^{\circ} \mathrm{C}$, hold $10 \mathrm{~min}$, programmed from 40 to $60{ }^{\circ} \mathrm{C}$ at $2{ }^{\circ} \mathrm{C} \mathrm{min}^{-1}$, and from 60 to $250{ }^{\circ} \mathrm{C}$ at $20^{\circ} \mathrm{C} \mathrm{min}^{-1}$, hold

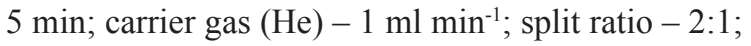
ionization - EI+ mode; acquisition parameters in full scan mode - scanned m/z 40-400.

The volatile compounds were identified by comparing their mass spectra with mass spectral libraries (Nist98) and by calculating linear retention indexes and comparing them with the literature data. All analyses were performed in triplicate. Compounds 
in the Tables are shown in the order of the retention time. As a quantitative measure, the share in the total GC peak area for each compound is given.

\section{Statistical analysis}

The experimental results were analyzed by Microsoft Excel 2010 and SPSS 17.00. Analysis of variance (ANOVA) and Tukey's test were used to determine differences among the samples. Differences were considered significant at $p<0.05$. Hierarchical cluster analysis was performed to classify horseradish genotypes in clusters depending on the composition of volatiles. The method used was the between-group linkage. The distances between samples were calculated using square Euclidean distances. As pre-treatment of data, transformation of the values of variables (average zero and standard deviation 1) called $Z$ scores was carried out. The dendrogram similarity scales that were generated by the SPSS program ranged from zero (greater similarity) to 25 (lower similarity). Similarities between the analyzed samples are presented in the dendrogram (see Fig. 1). The linear correlation analysis was performed in order to determine relationship between

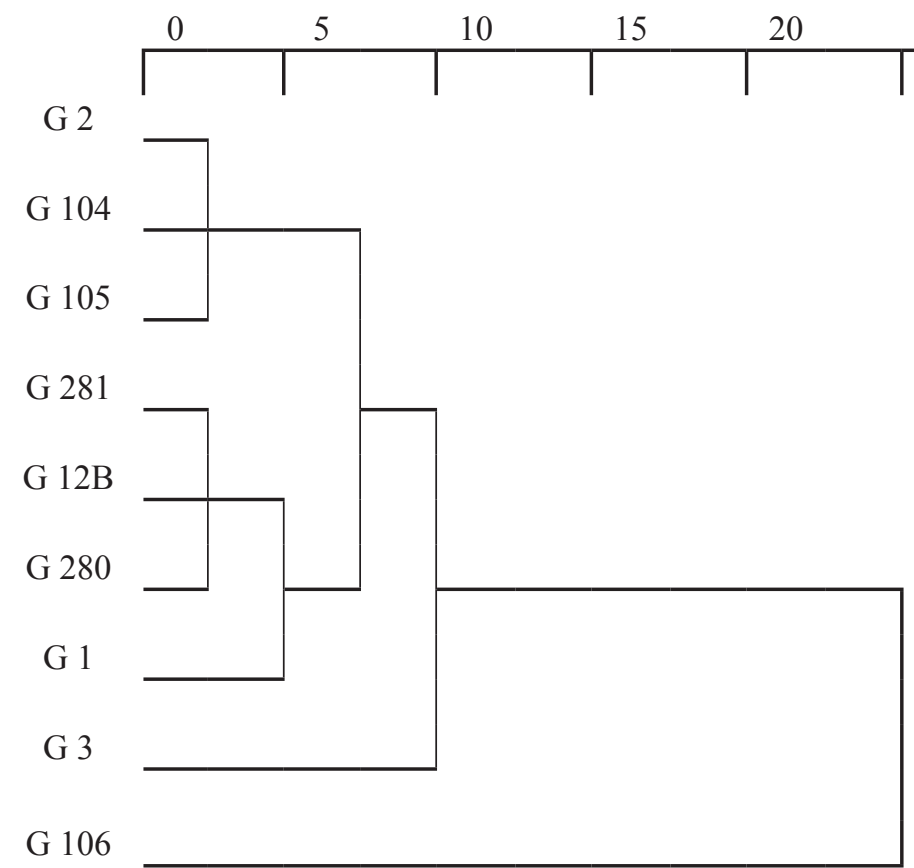

Fig. 1. The dendrogram obtained by hierarchical cluster analysis using means of the volatile compounds of horseradish roots.

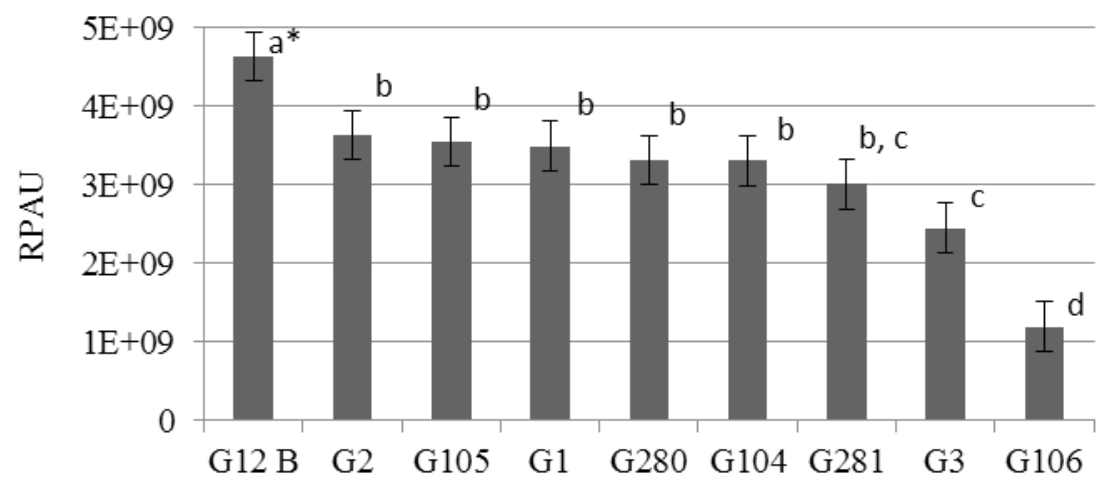

* Mean values within the same row followed by different letters (a, b, c, and d) significantly differ according to the LSD test $(p<0.05)$.

Fig. 2. RPAU (relative peak area units) of the volatile compounds of horseradish roots depending on the genotype. 
$\frac{\overline{0}}{\tilde{0}}$

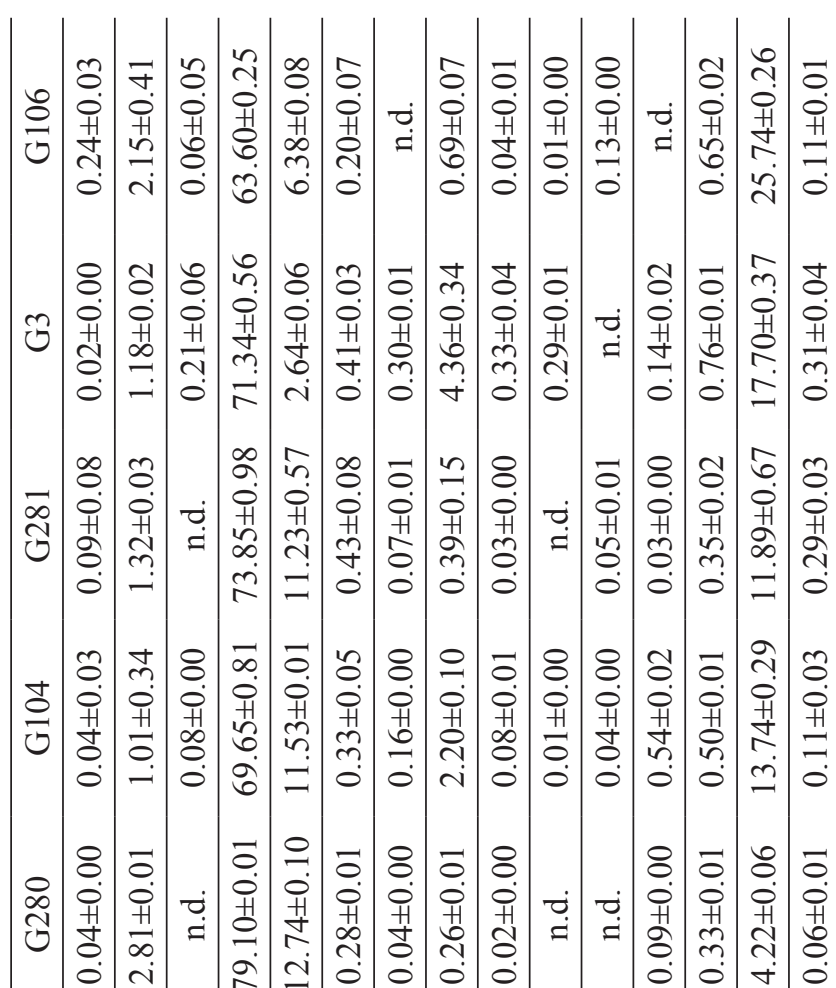

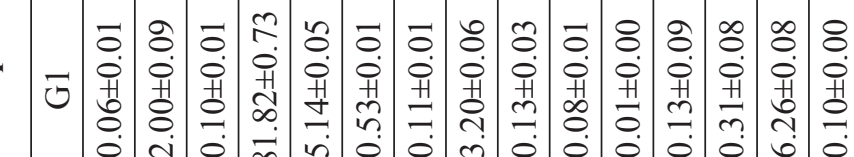

冚

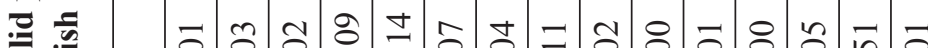

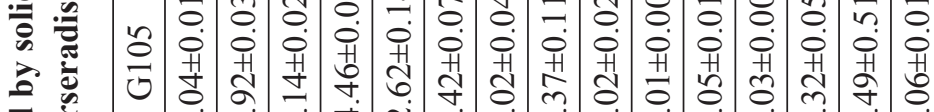

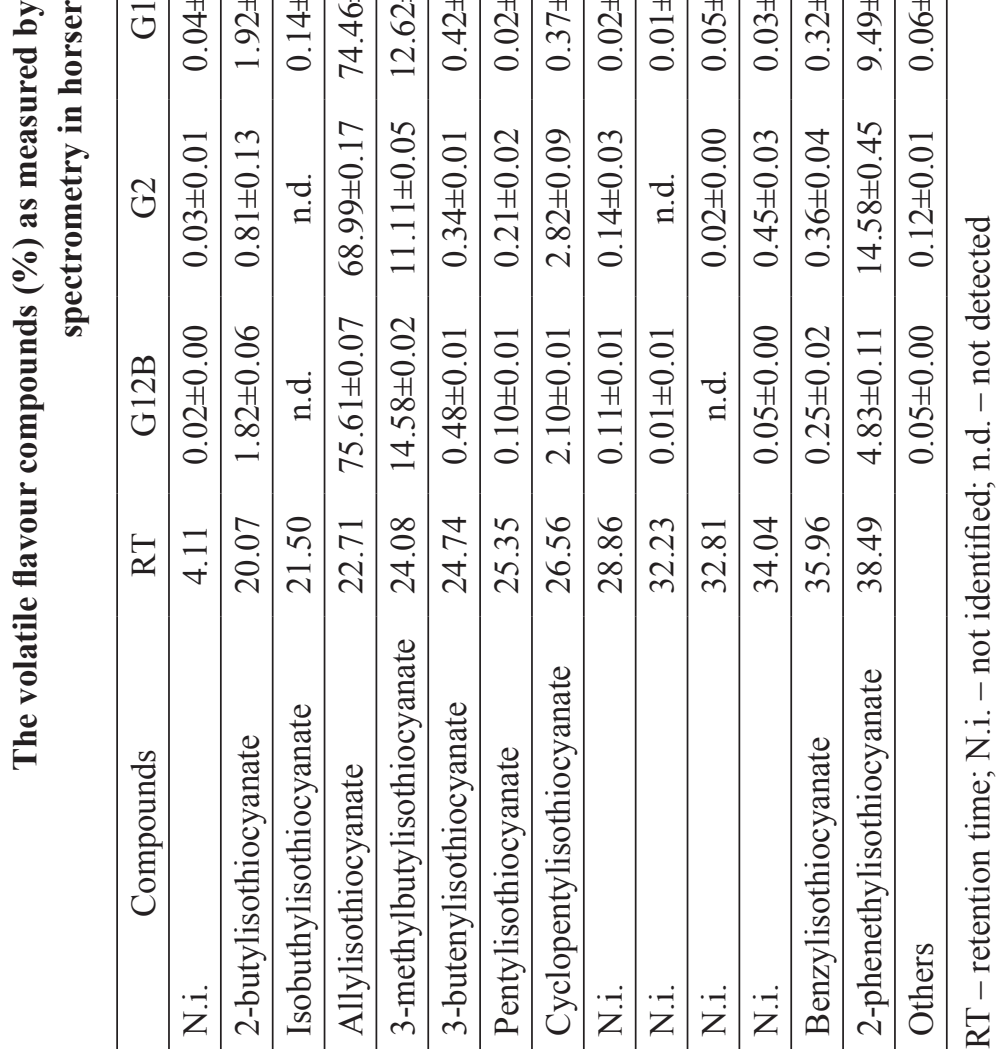


the volatile compounds. Differences were considered significant at $p<0.05$.

\section{Results and Discussion}

Volatile compounds released from foods are closely related to their aroma and can be used for quality assessment. The composition and content of volatiles vary greatly depending on the genetic background.

Our results of the total relative peak area (RPA) of the volatile compounds detected basing on the genotype origin showed that RPA of genotype G12B was significantly $(p<0.05)$ the highest, whereas genotypes G281, G3 and G106 had a significantly $(\mathrm{p}<0.05)$ lower RPA (Fig. 2).

Table 1 lists the major volatiles (more than $0.1 \%$ ) and some particular volatiles in each of the genotype. A total of 15 volatile compounds were detected, of which two were found only in some genotypes (IBuITC was found in G105, G1, G104, G3, and G106; pentyl-ITC - in all genotypes except G106). From the identified compounds, ITCs constituted the major class of volatiles (totally nine ITCs were identified); the main compound of all horseradish samples was AITC forming $64-82 \%$ of total identified volatile compounds.

The horseradish roots contained also significant $(p<0.05)$ amounts of 2-phenethyl-ITC, CPITC, and 2-butyl-ITC, and the highest concentration of these compounds was detected in genotypes G106, G3, and G280, respectively. Among the nine genotypes, the roots of G1, G104 and G105 contained the highest number of volatile compounds.

Korean researchers have reported that horseradish essential oil contains 94\% of AITC, an ITC-class compound (Park et al., 2006). Our results show a similar tendency - compared to other volatile compounds detected in horseradish roots, AITC was found in greatest amounts. According to the literature data, the most important volatile compounds detected in other plants also belong to the ITC class.

Researchers in Italy (Romeo, Ziino, Giuffrida, Condurso, \& Verzera, 2007) have found that sulphur compounds in the volatile fraction of pickled flower (Capparis spinosa L.) buds are MITC (441.22 ppm) and BITC (17.62 ppm). Another group of researchers (Kulisic-Bilusic, Schmöller, Schnäbele, Siracusa, \& Ruberto, 2012) have detected that MITC $(92.06 \%)$ is the main volatile compound in the essential oil from caper (Capparis spinosa L.), whereas BuITC and
sec-BuITC constitute only $0.38 \%$ and $0.25 \%$, respectively.

The results of our research demonstrated that the content of volatiles in horeseradish roots varied from $0 \%$ to $81.82 \%$ and depended on the genotype. Tukey's test revealed that differences between individual compounds in different genotypes were significant $(p<0.05)$. The highest content of IBuITC, CPITC and BITC was identified in G3, whereas genotype G106 had the greatest amount of 2-phenethyl-ITC. Also researchers from New Zealand have reported that volatile composition in Actinidia arguta is influenced by the genotype (Matich et al., 2003). There are research findings on aerial parts of six genotypes of Hyptis pectinata collected in different stages of maturation, demonstrating that the content of volatiles in the genotypes was different (ArrigoniBlank et al., 2008).

Regression and correlation analyses were performed to determine relationship between the volatile compounds (Table 2). A very strong positive correlation was found between the nonidentified compounds (28.86) and CPITC, but correlation between PEITC and AITC was very strong and negative $(p<0.01)$.

Hierarchical cluster analysis was applied to a data set of 15 variables (volatile compounds) and 9 genotypes of horseradish roots. The dendrogram (Fig. 1) shows that the samples of horseradish roots were not quite homogeneous. Besides, some genotypes markedly differed from the others. According to the hierarchical cluster analysis, at the distance of three, horseradish genotypes can be grouped as follows:

cluster A: genotypes 2, 104, and 105;

cluster B: genotypes 281, 12B, and 280;

cluster C: genotype 1;

cluster D: genotype 3;

cluster E: genotype 106.

The cluster analysis based on the concentrations of identified volatiles showed that genotypes G1, G3 and G106 separated out among other genotypes of horseradish samples by having lower levels of total aroma concentration (Fig. 1). Clusters obtained in our previous research basing on the total phenolic content and scavenging activity (Tomsone, Krūma, Lepse, \& Alsina, 2012) did not show any congruence with the grouping according to volatile composition made in the present research. This may be explained by the fact that volatile compounds and phenolic compounds are formed in the result of different biosynthetic processes (Velišek \& Cejpek, 2008). 
$\frac{N}{0}$

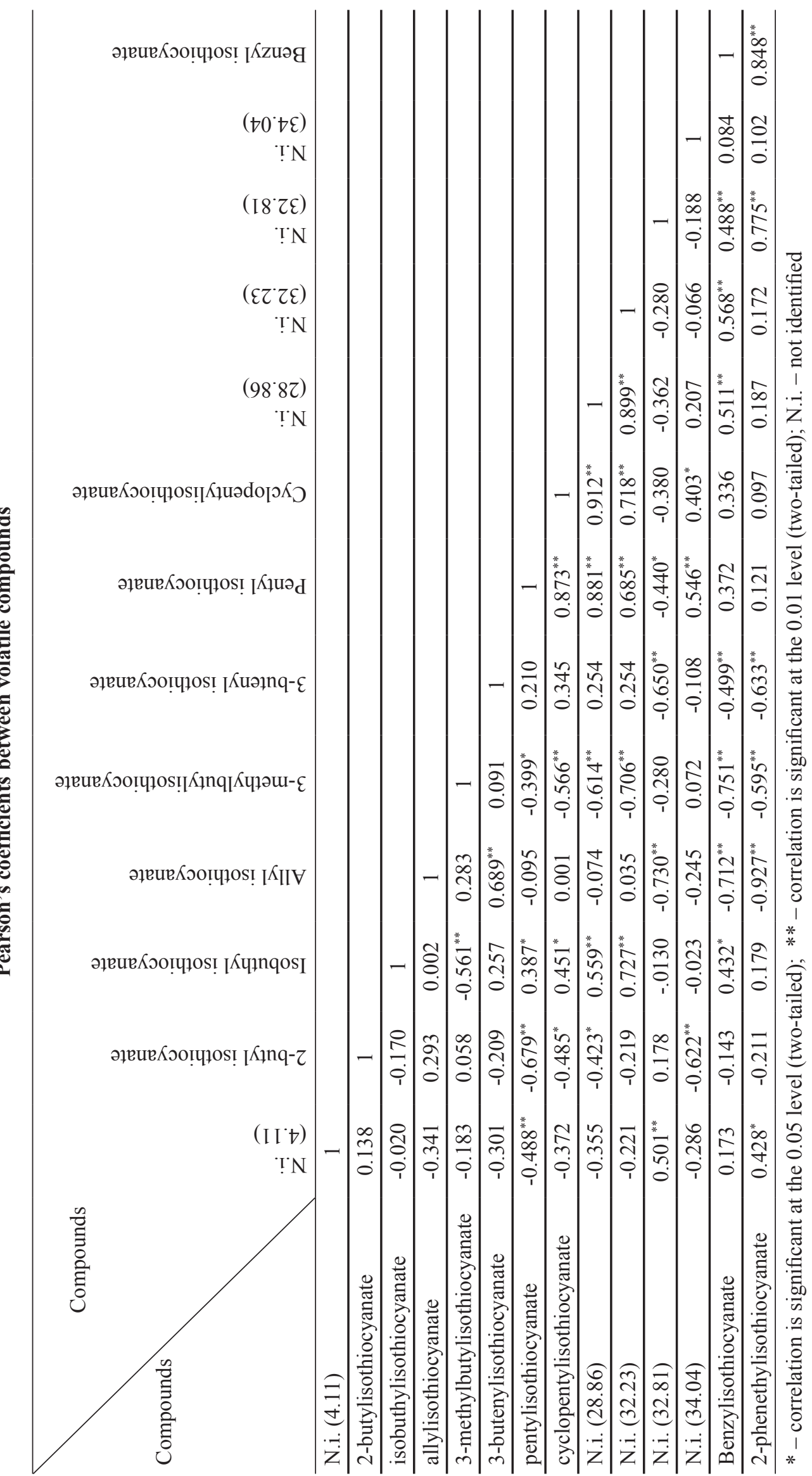




\section{Conclusion}

1. The genotype has an important impact on the content of volatile compounds of horseradish roots.

2. Totally 15 volatile compounds were detected.

3. From all the identified compounds, isothiocyanates constituted the major class of volatile compounds; the main compound of all horseradish samples was allylisothiocyanate forming $64-82 \%$ of total identified volatile compounds.

4. All horseradish samples contained large amounts of 2-phenylethylisothiocyanate (4-26\%) that is formed from glucosinolate - gluconasturtin.

5. Hierarchical cluster analysis can be performed to group the horseradish genotypes according to the composition of volatile compounds.

\section{References}

1. Afsharypuor, S., Jeiran, K., \& Jazy, A.A. (1998). First investigation of the flavor profiles of leaf, ripe fruit and root of Capparis spinosa var. mucronifolia from Iran. Pharmaceutica acta Helvetiae, 72, 307-309. DOI: 10.1016/S0031-6865(97)00023-X.

2. Andreasson, E., Jorgensen, L. B., Hoglund, A.S., Rask, L., \& Meijer, J. (2001). Different myrosinase and idioblast distribution in Arabidopsis and Brassica napus. Plant Physiology, 127(4), 1750-1763. DOI: 10.1104/ pp.010334.

3. Arrigoni-Blank, M.F., Antoniolli, A.R., Caetano, L.C., Campos, D.A., Blank, A. F., \& Alves, P.B. (2008). Antinociceptive activity of the volatile oils of Hyptis pectinata L. Poit. (Lamiaceae) genotypes. Phytomedicine, 15, 334-339. DOI: 10.1016/j.phymed.2007.09.009.

4. Bodnaryk, R.P., Luo, M., \& Kudryk, L. (1997). Effects of modifying the phytosterol profile of canola, Brassica napus L., on growth, development, and survival of the bertha armyworm, Mamestra confi gurata Walker (Lepidoptera: Noctuidae), the flea beetle, Phyllotreta cruciferae (Goeze) (Coleoptera: Chrysomelidae), and the aphids, Lipaphis erysimi (Kaltenbach) and Myzus persicae (Sulzer) (Homoptera: Aphididae). Canadian Journal of Plant Science, 77, 677-683. DOI: 93.177.194.180 on 10/10/12.

5. Bones, A.M., \& Rossiter, J.T. (1996). The myrosinase-glucosinolate system, its organization and biochemistry. Plant Physiology, 97(1), 194-208.
6. Bones, A.M., \& Rossiter, J.T. (2006). The enzymic and chemically induced decomposition of glucosinolates. Phytochemistry, 67(11), 1053 1067. DOI: 10.1016/j.phytochem.2006.02.024.

7. Dinkova-Kostova, A.T. (2008). The isothiocyanate sulforaphane induces the phase 2 response by signaling of the Keap1-Nrf2-ARE pathway: Implications for dietary protection against cancer. In Young-Joon Surh (Ed.), Dietary Modulation of Cell Signaling Pathways (pp. 206-227). LLC CRC Press.

8. Fahey, J.W., Zalcmann, A.T., \& Talalay, P. (2001). The chemical diversity and distribution of glucosinolates and isothiocyanates among plants. Phytochemistry, 56(1), 5-51. DOI: 10.1016/S0031-9422(00)00316-2.

9. Fenwick, G.R., Heaney, R.K., \& Mullin, W.J. (1983). Glucosinolates and their breakdown products in food and food plants. Food Science and Nutrition, 18, 123-201. DOI: 10.1016/0308-8146(83)90074-2.

10. Gaind, K.N., Gandhi, K.S., Junega, T.R., Kjær, A., \& Juhl, N.B. (1975). 4,5,6,7-tetrahydroxydecyl isothiocyanate derived from a glucosinolate in Capparis grandis. Phytochemistry, 14, 1415-1418. DOI: 10.1016/S0031-9422(00)98640-0.

11. Gamage, G.R., Park, H.J., \& Kim, K.M. (2009). Effectiveness of antimicrobial coated oriented polypropylene/polyethylene films in sprout packaging. Food Research International, 42, 832-839. DOI: 10.1016/j. foodres.2009.03.012.

12. Gil, V., \& MacLeod, A.J. (1980). The effects of $\mathrm{pH}$ on glucosinolate degradation by a thioglucoside glucohydrolase preparation. Phytochemistry, 19(12), 2547-2551. DOI: 10.1016/S0031-9422(00)83916-3.

13. Halkier, B.A., \& Gershenzon, J. (2006). Biology and biochemistry of glucosinolates. Annual Review of Plant Biology, 57, 303-333. DOI: 10.1146/annurev.arplant.57.032905.105228.

14. Kjaer, A. (1976). Glucosinolates in the cruciferae. In J.G. Vaughan, A.J. MacLeod \& B.M.G. Jons (Eds.), The Biology and Chemistry of the Cruciferae (pp. 207-219.). London: Academic Press.

15. Ko, J.A., Kim, W.Y., \& Park, H.J. (2012). Effects of microencapsulated Allyl isothiocyanate (AITC) on the extension of the shelf-life of Kimchi International. Journal of Food Microbiology, 153, 92-98. DOI: 10.1016/j. ijfoodmicro.2011.10.021. 
16. Kulisic-Bilusic, T., Schmöller, I., Schnäbele, K., Siracusa, L., \& Ruberto, G. (2012). The anticarcinogenic potential of essential oil and aqueous infusion from caper (Capparis spinosa L.). Food Chemistry, 132, 261-267.DOI:10.1016/j.foodchem.2011.10.074.

17. Li, C., Xue, F., Xu, Y., Ren, C., \& Pan, S. (2012). Influence of different gel complexes on flavour and colour change in Chongcai pastage. Food Chemistry, 130, 632-637. DOI: 10.1016/j. foodchem.2011.07.095.

18. Mari, M., Leoni, O., Bernardi, R., Neri, F., \& Palmieri, S. (2008). Control of brown rot on stonefruit by synthetic and glucosinolatederived isothiocyanates. Postharvest Biology and Technology, 47, 61-67. DOI: 10.1016/j. postharvbio.2007.06.003.

19. Matich, A.J., Young, H., Allen, J.M., Wang, M.Y., Fielder, S., McNeilage, M.A., \& MacRae, E.A. (2003). Actinidia arguta: volatile compounds in fruit and flowers. Phytochemistry, 63, 285-301. DOI: 10.1016/S0031-9422(03)00142-0.

20. Matthaus, B., \& Özcan, M. (2002). Glucosinolate composition of young shoots and flower buds of capers (Capparis species) growing wild in Turkey. Journal of agricultural and food chemistry, 50(25), 7323-7325. DOI: 10.1021/ jf020530+.

21. Matusheski, N.V., \& Jeffery, E.H. (2001). Comparison of the bioactivity of two glucoraphanin hydrolysis products found in broccoli, sulforaphane and sulforaphane nirile. Food Chemistry, 49(12), 5743-5749. DOI: 10.1021/jf010809a.

22. Mayton, H.S. (1996). Correlation of fungicidal activity of Brassica species with allylisothiocyanate production in macerated leaf tissue. Phytopathology, 86, 267-271.

23. Neoh, T.L., Yamamoto, C., Ikefuji, S., Furuta, T., \& Yoshii, H. (2012). Heat stability of allylisothiocyanate and phenylisothiocyanate complexed with randomly methylated $\beta$-cyclodextrin. Food Chemistry, 131, 11231131. DOI: 10.1016/j.foodchem.2011.09.077.

24. Olsson, K., \& Jonasson, T. (1994). Leaf feeding by caterpillars on white cabbage cultivars with different 2-propenyl glucosinolate (sinigrin). Journal of Applied Entomology, 118, 197-202. DOI: 10.1111/j.1439-0418.1994.tb00794.x.

25. Park, I.K., Choi, K.S., Kim, D.H., Choi, I.H., Kim, L.S., Bak, W.C., ... Shin, S.C. (2006). Fumigant activity of plant essential oils and components from horseradish (Armoracia rusticana), anise (Pimpinella anisum) and garlic (Allium sativum) oils against Lycoriella ingenua (Diptera: Sciaridae). Pest Management Science, 62, 723-728. DOI: 10.5897/AJB10.2023.

26. Pfalz, M., Vogel, H., Mitchell-Olds, T., \& Kroymann, J. (2007, June). Mapping of QTL for resistance against the crucifer specialist herbivore Pieris brassicae in a new Arabidopsis inbred line population, $\mathrm{Da}(1)-12$ x Ei-2 [Abstract]. PLoS One, 2(6):e578. Retrieved from PubMed database on the World Wide Web: http://www. ncbi.nlm.nih.gov/pubmed/17593977. DOI: 101371/journal.pone.0000578.

27. Raghavan Uhl, S. (2000). A to Z spices. In Handbook of Spices, Seasonings, and Flavorings (pp. 59-60). CRC Press LLC.

28. Rask, L., Andréasson, E., Ekbom, B., Eriksson, S., Pontoppidan, B., \& Meijer, J. (2000). Myrosinase: gene family evolution and herbivore defense in Brassiceae. Plant molecular biology, 42 (1), 93-113. DOI: 10.1023/A:1006380021658.

29. Romeo, V., Ziino, M., Giuffrida, D., Condurso, C., \& Verzera, A. (2007). Flavour profile of capers (Capparis spinosa L.) from the Eolian Archipelago by HS-SPME/GC-MS. Food Chemistry, 101, 1272-1278.

30. Shahidi, F., \& Gabon, J.E. (1990). Fate of sinigrin in methanol/ammonia/water-hexane extraction of B. juncea mustard seed. Journal of Food Science, 55, 793-795. DOI: 10.1111/ j.1365-2621.1990.tb05233.x.

31. Shroff, R., Vergara, F., Muck, A., Svatos, A., \& Gershenzon, J. (2008). Nonuniform distribution of glucosinolates in Arabidopsis thaliana leaves has important consequences for plant defense. Proceedings of the National Academy of Sciences of the United States of America, 105, 6196-6201.

32. Tlili, N., Elfalleh, W., Saadaoui, E., Khaldi, A., Triki, S., \& Nasri, N. (2011). The caper (Capparis L.): Ethnopharmacology, phytochemical and pharmacological properties. Fitoterapia, 82, 93-101. DOI: 10.1016/j. fitote.2010.09.006.

33. Tomsone, L., Krūma, Z., Lepse, L., \& Alsina, I. (2012). The application of hierarchical cluster analysis to clasify genotypes of horseradish (Armoracia rusticana L.) roots. In Conference program and abstracts of the 7th Baltic Conference on Food Science 
and Technology, 17-18 May 2012 (p. 102). Kaunas, Lithuania: Kaunas University of Technology.

34. Velišek, J., \& Cejpek, K. (2008). Phenolic compounds. In V. Šedivy (Ed.), Biosynthesis of food components (pp. 314-372). OSSIS.

35. Whitmore, B.B., \& Naidu, A.S. (2000). Glucosinolates. In A.S. Naidu (Ed.), Natural Food Antimicrobial Systems (pp. 1-18). CRC Press LLC.
36. Wittstock, U., \& Halkier, B.A. (2002). Glucosinolate research in the Arabidopsis era. Trends in Plant Science, 7(6), 263-270. DOI: 10.1016/S1360-1385(02)02273-2.

37. Wu, X., Kassie, F., \& Mersch-Sundermann, V. (2005). Induction of apoptosis in tumor cells by naturally occurring sulfur-containing compounds. Mutation Research/Reviews in Mutation Research, 589, 81-102. DOI: 10.1016/j.mrrev.2004.11.001.

\section{Acknowledgement}

The research has been performed within the framework of the "Osmose" project between Latvia University of Agriculture and National Polytechnic Institute of Toulouse entitled "Comparison of composition and properties of forgotten aromatic plants and fungi of Latvia and Midi-Pyrenees" (Comparaison des compositions et proprietes phytochimiques de plantes-champignons aromatiques oublies lettons et MidiPyreneens). The authors acknowledge financial support of the ERAF project „Promotion of scientific activities of LLU”, contract No. 2010/0198/2DP/2.1.1.2.0/10/APIA/VIAA/020. The authors also acknowledge the Püre Horticultural Research Centre for the supply of horseradish roots. 